\title{
Mechanism related to reduction of intraocular pressure by melanocortins in rabbits
}

\author{
N Naveh, A Kaplan-Messas, J Marshall
}

\begin{abstract}
Aim-To investigate whether the ocular hypotensive effect of alpha melanocyte stimulating hormone (MSH) is related to eicosanoids or cyclic AMP (cAMP).

Methods-Intraocular pressure (IOP) readings were taken at a similar time on the day before and after a single dose of topical MSH. Changes in the levels of prostaglandin $\mathrm{E}_{2}\left(\mathrm{PGE}_{2}\right)$ and prostacyclin in incubated iris ciliary body (ICB) explants were measured by specific radioimmunoassay (RIA). Incubated ICB explants were exposed to MSH or adrenaline (epinephrine) for a week. In addition, cAMP levels in the medium were determined following short term incubation using RIA.
\end{abstract}

Results-A significant dose related reduction in IOP was noted with topical MSH (mean (SD) maximal effect 4.5 (0.1) $\mathrm{mm} \mathrm{Hg} \mathrm{(21 \% );} \mathrm{p} \mathrm{<0.001} v$ appropriate baseline) which persisted up to 6 hours $(p=0.05)$. MSH treated ICB explants showed a 1.5-fold increase in $\mathrm{PGE}_{2}$ and prostacyclin levels $(\mathrm{p}<0.001$ for each parameter) while cAMP levels were increased twofold $(\mathrm{p}<0.001)$.

Conclusions-A single application of MSH caused a sustained dose related ocular hypotensive effect with no side effects. An increase in eicosanoid and cAMP levels following ICB exposure to MSH indicated their involvement in MSH induced ocular hypotension. MSH and its analogues might have clinical relevance as antiglaucoma drugs with fewer side effects because of their antiallergic and antiinflammatory properties.

(Br f Ophthalmol 2000;84:1411-1414)

Research Institute, $\mathrm{Tel}$

Aviv University School of Medicine, Sheba

Medical Center, Israel

N Naveh

A Kaplan-Messas

Rayne's Institute, St Thomas's Hospital,

London, UK

J Marshall

Correspondence to:

Professor N Naveh, 15 Rav

Ashi St, Tel Aviv 69395,

Israel

hnave@zahav.net.il

Accepted 23 June 2000

Alpha melanocyte stimulating hormone $(\mathrm{MSH})$ is a basic tridecapeptide which originates from pro-opiomelanocortin (POMC) found in the pituitary, ${ }^{1}$ brain, ${ }^{2}$ skin, ${ }^{3}$ and at other sites. ${ }^{4}$ POMC is the precursor for a family of biologically active peptides called melanocortins which include alpha, beta and gamma MSH, lipotropins, endorphins, and adrenocorticotrophic hormone (ACTH). $\mathrm{MSH}$, named after its effect on the pigmentation of amphibian skin, is involved in modulation of neuroprotection, anti-inflammatory activity, ${ }^{5-7}$ and obesity regulation. ${ }^{8}$ Its effect is receptor specific and is not duplicated by ACTH, ACTH fragments, or glucocorticosteroids. $^{9} 10$

In the eye MSH has been identified as a constitutive component of the normal aqueous humour of humans, rabbits, and mice. ${ }^{11}{ }^{12}$ Its involvement in the regulation of intraocular pressure (IOP) was first noted in the 1960s and 1970s when high doses of the hormone were found to have a biphasic effect on IOP. ${ }^{13-15}$

Melanocortins act by the activation of $G$ protein coupled receptors and production of cyclic AMP (cAMP). ${ }^{16}$ Cyclic AMP modulates IOP reduction by adrenergic agonists ${ }^{17} 18$ and prostaglandin derivatives such as latanoprost. ${ }^{19}{ }^{20}$ Enhancement of eicosanoid production by MSH treated ocular pigmented epithelium $^{21}$ is another possible role for melanocortins in the regulation on IOP. The activity of melanocortins in most organs is dose related so we have examined its role in IOP regulation using physiological doses,${ }^{22}{ }^{23}$ unlike previous studies. ${ }^{13-15}$ 24-26

In this study we have investigated whether MSH causes a sustained reduction in IOP following a single topical application of alpha MSH in normotensive pigmented rabbits.

\section{Materials and methods}

ANIMALS

Normotensive pigmented rabbits of either sex weighing $2-3.5 \mathrm{~kg}$ were housed in standard cages in a temperature controlled room with free access to water and food (Laboratory Rabbit Chow, Kalston Purina Co) and were exposed to a 12 hour light-dark cycle. Institutional guidelines regarding animal experimentation were followed. During IOP measurements the rabbits were kept conscious.
IRIS CILIARY BODY (ICB) SAMPLE PREPARATION The cornea and anterior segment were removed and the ICB was pulled gently and maintained for 5 days in a 24 well culture well (Nunc, Roskilde, Denmark) containing DMEM and $10 \%$ calf serum, and supplemented with penicillin $(100 \mathrm{U} / \mathrm{ml})$, streptomycin $(100 \mu \mathrm{g} / \mathrm{ml})$, and glutamine $(2 \mathrm{nM})$ at $37^{\circ} \mathrm{C}$ in a humidified atmosphere of $10 \%$ carbon dioxide in air. 
Table 1 Effects of melanocyte stimulating hormone (MSH) on intraocular pressure (IOP)

\begin{tabular}{llll}
\hline $\begin{array}{l}\text { Time after } \\
\text { application (hours) }\end{array}$ & MSH $\left(10^{-8} M\right)$ & MSH $\left(10^{-9} M\right)$ & MSH $\left(10^{-10} M\right)$ \\
\hline 0 (baseline) & $24(0.3)$ & $23(0.8)$ & $24(0.5)$ \\
1 & $23(0.7) ;(4.2 \%)$ & $23(0.7) ;(0 \%)$ & $24(0.5) ;(0 \%)$ \\
2 & $19(0.6) ;(21 \%)^{\star}$ & $20(0.5) ;(13 \%)^{\star}$ & $23(0.7) ;(4.2 \%)$ \\
4 & $20(0.5) ;(17 \%)^{\star}$ & $20(0.5) ;(13 \%)^{\star}$ & $20(0.5) ;(17 \%)^{\star}$ \\
6 & $21(0.4) ;(12.5 \%)^{\star}$ & $22(0.7) ;(10 \%)$ & $23(0.5) ;(4.2 \%)$
\end{tabular}

Values are mean (SD) with \% IOP reduction.

${ }^{\star} \mathrm{p}<0.05$ compared with untreated baseline values of treated eyes at the same time.

PROSTAGLANDIN E 2 AND PROSTACYCLIN DETERMINATION

Samples of the medium were obtained 2, 5, and 7 days after the start of ICB incubation and processed as described previously ${ }^{21}$ for determination of $\mathrm{PGE}_{2}$ and 6-keto $\mathrm{PGF}_{1 \alpha}$ (the stable prostacyclin metabolite) using the appropriate radioimmunoassay (RIA) kits (Amersham NEN, USA).

CYCLIC AMP DETERMINATION

Medium samples were taken 2 days after starting incubation and cAMP was determined by RIA (Amersham NEN, USA).

MEASUREMENTS OF IOP

IOP was measured in conscious rabbits using a Digilab model $30 \mathrm{R}$ as described previously ${ }^{27}$ after topical application of one drop of local anaesthetic (Localin-Benoxinate $\mathrm{HCl} 0.4 \%$, Fischer Pharmaceuticals, Israel) diluted 1:3 with sterile saline. The exclusion criteria were a consistent difference in IOP between the two eyes of $2 \mathrm{~mm} \mathrm{Hg}$ or more, irritability, or any sign of ocular irritation.

A baseline IOP curve was plotted for each animal 1 day before treatment at 09.00, 11.00, $12.00,13.00$, and 15.00 . The following day the drugs were applied topically at 08.00 to the right eye only and IOP readings were then taken at both eyes at similar times to the baseline curve, thus avoiding individual and seasonal changes in IOP. ${ }^{2127}$

DRUG PREPARATION

MSH acetate (Sigma Chemical Co, St Louis, MO, USA) was dissolved in sterile saline $(0.9 \% \mathrm{NaCl})$. The stock solution containing $250 \mu \mathrm{g} / \mathrm{ml}\left(10^{-4} \mathrm{M}\right)$ was stored at $-20^{\circ} \mathrm{C}$ and diluted with phosphate buffered saline (PBS) for topical application according to the protocol described.

STUDY DESIGN

The study consisted of in vivo and in vitro experiments.

In vivo study

This was a randomised, double blind, single dose study. IOP readings were taken as

Table 2 Effect of melanocyte stimulating hormone (MSH) on eicosanoid production by iris ciliary body

\begin{tabular}{llllll}
\hline & \multicolumn{2}{l}{$\mathrm{PGE}_{2}(\mathrm{pg} / \mathrm{mg})$} & & \multicolumn{2}{l}{ 6-Keto- $P G F_{2 a}(\mathrm{pg} / \mathrm{mg})$} \\
\cline { 2 - 3 } Time of incubation & Control & MSH $(n=10)$ & & Control & MSH $(n=10)$ \\
\hline Day 2 & $900(50)$ & $1550(100)^{\star}$ & & $250(15)$ & $400(20)^{\star}$ \\
Day 5 & $300(40)$ & $440(15)^{\star}$ & & $75(20)$ & $130(15)^{\star}$ \\
Day 7 & $220(60)$ & $330(20)^{\star}$ & & $50(10)$ & $80(15)^{\star}$ \\
\hline${ }^{\star} \mathrm{p}<0.05$. & & & &
\end{tabular}

described. The drugs were bottled in an identical manner and coded; decoding took place only at completion of the statistical analysis.

The in vivo study involved four groups of animals: control untreated rabbits (group 1) and groups 2-4 treated with MSH in concentrations of $10^{-8}, 10^{-9}$, and $10^{-10}$, respectively. The baseline IOP curve was determined and the following day the drugs were applied topically at 08.00 to the right eye only and IOP readings were then taken in both eyes at similar times. The effect of the drug on the IOP was calculated in $\mathrm{mm} \mathrm{Hg}$ and was also expressed as a percentage (\% IOP) of baseline as follows:

$\%$ IOP $=\left(\right.$ baseline $\mathrm{IOP}^{\star}$ - treated $\left.\mathrm{IOP}^{\star \star}\right) /$ baseline IOP

where baseline $\mathrm{IOP}^{\star}$ indicates the value at a given time.

In vitro study

Long term incubation involved determination of $\mathrm{PGE}_{2}$ and $\mathrm{PGF}_{1 \alpha}$ levels in the medium of ICB whole explants incubated with $\mathrm{MSH}$ at a final concentration of $10^{-8}$ (group 1) and incubated in adrenaline (epinephrine) 1\% (group 2). Samples were obtained for eicosanoid measurements at 2, 3, and 7 days while medium sampling for cAMP was done on day 2 only.

Short term incubation explants lasted 90 minutes at $37^{\circ} \mathrm{C}$ in a shaking bath after which a sample was obtained for cAMP measurements in the following groups: group 1 (control; no drug added); group 2 (treated with forskolin); groups 3 and 4 (treated with $\mathrm{MSH}$ at final concentrations of $1 \mathrm{nM}$ and $10 \mathrm{nM}$, respectively).

STATISTICAL ANALYSIS

IOP reduction was calculated by comparing the measured value in $\mathrm{mm} \mathrm{Hg}$ at each time point in the treated eye with the corresponding baseline measurement before treatment. Comparison of the IOP values was performed by analysis of variance (ANOVA) and the Student's $t$ test.

\section{Results}

EFFECT OF MSH ON INTRAOCULAR PRESSURE

A single application of MSH caused a dose related reduction in IOP (Table 1). The maximal hypotensive effect was seen 2 hours after application of $10^{-8} \mathrm{M} \mathrm{MSH}$ (mean (SD) reduction in IOP $4.5(0.1) \mathrm{mm} \mathrm{Hg} ; 21 \%$ of baseline) and this lowering effect persisted at 4 hours $(17 \%)$ and at 6 hours $(p<0.001$ and $\mathrm{p}=0.05$ compared with the corresponding baseline levels, respectively). The reduction of IOP with $\mathrm{MSH}$ in a concentration of $10^{-9} \mathrm{M}$ was smaller than that achieved with $10^{-8} \mathrm{M}$ ( $13 \%$ at 2 and 4 hours, $p<0.05$ for each) while MSH in a concentration of $10^{-10} \mathrm{M}$ caused a transient reduction in IOP (Table 1). IOP changes in the contralateral eye treated with $\mathrm{MSH}$ were negligible, and no other side effects were noted.

EFFECT OF MSH ON EICOSANOID LEVELS IN ICB The concentrations of both $\mathrm{PGE}_{2}$ and 6-keto $\mathrm{PGF}_{1 \alpha}$ in the conditioned media of control ICB 
Table 3 Adrenergic drug and prostaglandin $E_{2}\left(P G E_{2}\right)$ production by iris ciliary body (ICB)

\begin{tabular}{lc}
\hline Group & $P G E_{2}(p g / m g)$ \\
\hline Control & $980(150)$ \\
Saline & $1090(200)$ \\
Adrenaline $1 \%$ & $2470(310)^{\star}$ \\
MSH & $1550(290)^{\star}$ \\
\hline
\end{tabular}

Sampling was done on day 2 of ICB incubation. ${ }^{\star} \mathrm{p}<0.05 v$ control group.

Table 4 Melanocyte stimulating hormone (MSH) and cyclic AMP (cAMP) in iris ciliary body

\begin{tabular}{|c|c|}
\hline Group & 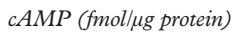 \\
\hline Control & $11(0.5)$ \\
\hline Forskolin & $27(1.5)^{\star}$ \\
\hline MSH $(1 \mathrm{nM})$ & $19(3)^{\star}$ \\
\hline MSH $(10 \mathrm{nM})$ & $21(4)^{\star}$ \\
\hline
\end{tabular}

explants decreased during the first 7 days in culture (Table 2). Eicosanoid levels in MSH treated ICB explants were significantly higher than in the corresponding untreated explants during the first week of culture $(p<0.001$ at days 2,5 , and 7 for each $v$ corresponding control). In order to test whether the reduced response of cultured explants to $\mathrm{MSH}$ over time could be attributed to degenerative changes, the hormone was added on day 5 to incubated but untreated retinal explants. This resulted 2 days later in a 1.5 increase in $\mathrm{PGE}_{2}$ levels $(p<0.0025)$, similar to the average increase observed on day 7 in ICB explants treated with the hormone from the start of incubation (data not shown). Addition of adrenaline to the incubation medium containing ICB caused a 2.5 increase in $\mathrm{PGE}_{2}$ levels in the medium $(p<0.001 v$ control or saline groups) on day 2 (Table 3 ).

CYCLIC AMP AND ICB EXPLANT CULTURE

Cyclic AMP levels in the incubation medium containing $\mathrm{MSH}$ treated ICB were dose related, reaching maximal values which were twice as high as those in the control medium at a concentration of $10 \mathrm{nM}$ (Table 4).

\section{Discussion}

The ocular effect of MSH, first studied in the 1960 s, has a biphasic IOP pattern ${ }^{13-15}$ but the hypotensive phase has been overlooked. This study is the first to demonstrate that a single application of $\mathrm{MSH}$ induces a significant dose related reduction in IOP in rabbits. The maximal MSH induced decrease in IOP averaged $21 \%$ below baseline 2 hours after application, and was still statistically significant 4 and 6 hours later. Changes in IOP in the contralateral eye treated with $\mathrm{MSH}$ were negligible, and no other side effects were noted.

The finding that the MSH induced ocular hypotensive effect is dose related is in accordance with the fact that the activity of the drug is dose dependent in the nervous system, ${ }^{6}$ skin, ${ }^{3}$ and as an anti-inflammatory agent..$^{5-7}$ In our study the MSH induced ocular hypotensive effect was achieved with doses which were in the range of normal MSH levels in the rabbit aqueous. ${ }^{11}$ In most previous studies MSH was used in non-physiological doses ${ }^{17} 24-2628$ causing flare and increased IOP. ${ }^{13}{ }^{15}{ }^{17}$ Krakau's findings ${ }^{13}$ on MSH induced IOP increase and flare were possibly caused by inaccurate methodology. Another group, ${ }^{28}$ using $\mathrm{MSH}$ in higher doses, reported no ocular side effects. Likewise, Hernandez et al injected $\mathrm{MSH}$ intracamerally ${ }^{29}$ at a dose one million times greater than normal aqueous values, using a traumatic process. In these extreme nonphysiological conditions no reliable conclusions can be drawn about the effect of $\mathrm{MSH}$ on IOP or flare.

The dose related biphasic effect of $\mathrm{MSH}$ is reminiscent of the early data on the ocular biphasic effect of prostaglandins reported in the $1970 \mathrm{s.}^{3031}$ The intracameral injection of prostaglandins produced a dose related initial hypertensive phase associated with a transient protein leakage into the aqueous.

The regulatory effect of $\mathrm{MSH}$ in pregnant women has not been suggested although it is well established that the IOP is reduced in normotensive and ocular hypertensive pregnant women during the second trimester of pregnancy. ${ }^{32-38}$ At this time plasma levels of $\mathrm{MSH}$ in the mother are higher than normal ${ }^{36} 37$ owing to excessive production by the embryo and placenta. ${ }^{37} 38$ Our results showing MSH induced reduction in IOP indicate that $\mathrm{MSH}$ might be the protagonist in inducing ocular hypotension in pregnant women.

The mechanism by which MSH exerts its ocular hypotensive effect is as yet unknown. We have shown that MSH induces cAMP production in vitro by ICB; cAMP is involved in modulating IOP reduction by adrenergic agonists $^{17}{ }^{18}$ while adenosine agonists lower IOP. ${ }^{18}$ Thus, cAMP production by ICB in eyes exposed to MSH might be one of the underlying mechanisms for the ocular hypotensive effect of MSH. This is in agreement with the fact that melanocortins act by activation of $G$ protein coupled receptors and production of cAMP. ${ }^{16}$ Our study also found an increase in eicosanoid production by incubated ICB over a long incubation period. Adrenaline caused a similar increase in $\mathrm{PGE}_{2}$ levels, which is in accordance with the finding that adrenergic agents with ocular hypotensive activity act partially through endogenous eicosanoid. The ocular hypotensive effect of various eicosanoid analogues is well established and latanoprost is currently used as an antiglaucoma agent. ${ }^{39}$ It therefore seems likely that the IOP reducing effect of MSH is also related to an increase in eicosanoid levels.

Activation of adrenergic receptors regulating permeability of the blood-aqueous barrier might also play a part in the hypotensive activity of MSH which requires intact $\beta$ adrenergic receptor sites, ${ }^{50}$ while the anti-inflammatory effect of centrally administered MSH is inhibited by the systemic injection of non-specific $\beta$ adrenergic receptor blockers. ${ }^{5}$

In summary, we have shown that $\mathrm{MSH}$ at physiological doses induces a significant and sustained reduction in IOP in normotensive rabbits. The hypotensive effect seems to be attributable to activation by MSH of cAMP, its 
second messenger, and enhanced eicosanoid production.

The mechanism of action of melanocortins in regulating IOP still has to be determined but it is probably multifactorial and may include a modulatory effect of MSH on the blood-aqueous barrier through adrenergic receptors.

We are grateful to $\mathrm{Mr}$ Chaim Naveh for his skilful technical assistance and extensive research.

$\mathrm{NN}$ and JM have a proprietary interest in the subject.

1 Eberle AN, Verin VJ, Solca F, et al. Biologically active monoiodinated alpha-MSH derivatives for receptor binding studies using human melanoma cells. 7 Recept Res 1991;11:1-4, 311-22

2 Arai H, Moroji T, Kosaka K, et al. Extrahypophyseal distribution of alpha-melanocyte stimulating hormone (alphaMSH)-like immunoreactivity in postmortem brains from normal subjects and Alzheimer-type dementia patients. Brain Res 1986;377:7-9, 305-10.

3 Hunt G. Melanocyte-stimulating hormon: a regulator of human melanocyte physiology. Pathobiology 1995;63:1221 .

4 Star RA, Rajora N, Huang J, et al. Evidence of autocrine modulation of macrophage nitric oxide synthase by alphamoct Acad Sci USA 1995;92:8-15, 8016-20

5 Macaluso A, McCoy D, Ceriani G, et al. Antiinflammatory influences of alpha-MSH molecules: central neurogenic and peripheral actions. F Neurosci 1994;14:2377-82.

6 Ceriani G, Macaluso A, Catania A, et al. Central neurogenic antiinflammatory action of $\alpha \mathrm{MSH}$ : modulation of peripheral inflammation induced by cytokines and other mediators of inflammation. Neuroendocrinology 1994;59:138-43.

7 Hiltz ME, Catania A, Lipton JM. Alpha-MSH peptides inhibit acute inflammation induced in mice by IL-1 beta, IL-6, TNF-alpha and endogenous pyrogen but not caused by LTB4, PAF and IL-8. Cytokine 1992;4:320-8.

8 Gunn TM, Miller KA, He L, et al. The mouse mahogany locus encodes a transmembrane form of human attractin. Nature 1999;398:152-6.

9 Kastin AJ, Beach GD, Hawley WD, et al. Dissociation of MSH and ACTH release in man. $\mathcal{F}$ Clin Endocrinol Metab 1973;36:770-2.

10 Schioth HB, Muceniece R, Wikberg JE. Characterization of the binding of MSH-B, HB 228, GHRP- 6 and $153 \mathrm{~N}-6$ to the human melanocortin receptor subtypes. Neuropeptides 1997;31:565-71

11 Taylor AW, Streilein JW, Cousins SW. Identification of alpha-melanocyte stimulating hormone as a potential immunosuppressive factor in aqueous humor. Curr Eye Res 1992;11:1199-206

12 Knisely TL, Hosoi J, Nazareno R, et al. The presence of biologically significant concentrations of glucocorticoids but little or no cortisol binding globulin within aqueous humor: relevance to immune privilege in the anterior chamber the eye. Invest Ophthalmol Vis Sci 1994;35:3711-23.

13 Dyster-Aas HK, Krakau CET. A photo-electric instrument for measuring the aqueous flare in the intact eye. Ophthalmologica $1963 ; 146: 48-56$.

14 Dyster-Aas HK, Krakau CET. General effects of alphamelanocyte stimulating hormone in the rabbit. Acta Endo-

15 Dyster-Aas K, Krakau CET. Increased permeability of the blood-aqueous humor barrier in the rabbit's eye provoked by melanocyte stimulating peptides. Endocrinology 1964;74 255-65.

16 Abdel-Malek ZA, Swope VB, Trinkle LS, et al. Stimulation of Cloudman melanoma tyrosinase activity occurs predominantly in G2 phase of the cell cycle. Exp Cell Res 1989;180:198-208.

17 Neufeld AH, Jampol LM, Sears ML. Aspirin prevents the disruption of the blood-aqueous barrier in the rabbit eye. Nature 1972;238:7-21, 158-9.
18 Crosson CE. Adenosine receptor activation modulates intraocular pressure in rabbits. F Pharmacol Exp Ther 1995; 273:320-6.

19 Yousufzai SY, Zheng P, Abdel-Latif AA. Muscarinic stimulation of arachidonic acid release and prostaglandin synthesis in bovine ciliary muscle: prostaglandins induce cyclic AMP formation and muscle relaxation. Exp Eye Res 1994;58:513-22.

20 Hyatt PJ, Bell JBG, Bhatt K, et al. Effect of alphamelanocyte-stimulating-hormone on the cyclic AMP and phospholipid metabolism of rat adrenocortical cells. 7 Endocrinol 1986;110:405-16.

21 Bar-Ilan A, Savion N, Naveh N, et al. Alpha melanocyte stimulating hormone (alpha-MSH) enhances eicosanoid production by bovine retinal pigment epithelium. Prostaglandins 1992;43:31-44; erratum 1992;43:502.

22 Bauer B, Ehinger B. Action of alpha-MSH on the release of neurotransmitters from the retina. Acta Physiol Scand 980;108:105-7.

23 Goodall T, Buffey JA, Rennies IG, et al. Effect of melanocyte stimulating hormone on human cultured choroidal melanocytes, uveal melanoma cells, and retinal epithelial cells. Invest Ophthalmol Vis Sci 1994;35:826-37.

24 Bengtsson E. The effect of imidazole on the disruption of the blood-aqueous barrier in the rabbit eye. Invest Ophthalmol Vis Sci 1976;15:315-20.

25 Bengtsson E. The effect of theophylline on the breakdown of the blood-aqueous barrier in the rabbit eye. Invest Ophthalmol Vis Sci 1977;16:636-40.

26 Bengtsson E, Ehinger B. The effect of experimental uveitis on the uptake of prostaglandin E1 in the rabbit iris-ciliary body. Acta Ophthlmol (Copenh) 1977;55:688-95

27 Naveh N, Benita S, Muchtar S. Pilocarpine incorporated into submicron vehicle causes an unexpectedly prolonged ocular hypotensive effect in rabbits. F Ocul Pharmacol 1997;10:509-20.

28 Kastin AJ, Kullander S, Borglin NE, et al. Extrapigmentary effects of melanocyte-stimulating hormone in amenorrhoeic women. Lancet 1968;i:1007-10.

29 Hernandez DE, Simons KB, Spampinato D, et al. Intracameral administration of alpha-MSH increases intraocular pressure in rabbits. Neuropeptides 1985;6:553-9.

30 Bito LZ. Prostaglandins: a new approach to glaucoma management with new intriguing side effects. Surv Ophthalmol 1977;41(Suppl2): S1-14.

31 Dyster-Aas HK, Kastin AJ, Vidacovich RP, et al. Melanocyte-stimulating activity in serum and the aqueous flare response in rabbits. $\mathcal{F}$ Endocrinol 1970;46:285-6.

32 Philips CL, Gore SM. Ocular hypotensive effect of late pregnancy with and without high blood pressure. $\mathrm{Br} F \mathrm{Oph}$ thalmol 1985;69:117-9.

33 Quershi IA. Intraocular pressure and pregnancy: a comparison between normal ocular hypertensive subjects. Arch Med Res 1997;28:397-400

34 Quershi IA, Xi XR, Wu XD. Intraocular pressure trends in pregnancy and in the third trimester hypertensive patients. Acta Obstet Gynecol Scand 1996;75:816-9.

35 Goland RS, Conwell IM, Warren WB, et al. Placental corticotropin-releasing hormone and pituitary-adrenal function during pregnancy. Neuroendocrinology 1992;56: $742-9$.

36 Clark D, Thody AJ, Shuster S, et al. Immunoreactive alphaMSH in human plasma in pregnancy. Nature 1978;273: 163-4.

37 Silman RE, Chard T, Rees LH, et al. Proceedings: Observations on melanocyte-stimulating hormone-like peptides in human maternal plasma during late pregnancy. $\mathcal{f}$ Endocrinol 1975;65:46-7.

38 Mauri A, Volpe A, Martellotta MC, et al. Alpha-melanocytestimulating hormone during human perinatal life. 7 Clin Endocrinol Metab 1993;77:113-7.

39 Camras CB, Schumer RA, Marsk A, et al. Intraocular pressure reduction with PhXA34, a new prostaglandin analogue, in patients with ocular hypertension. Arch Ophthalmol 1992;110:1733-8.

40 Holmdahl G, Bengtsson E. The effect of timolol maleate on the disruption of the blood-aqueous barrier in the rabbit eye. Invest Ophthalmol Vis Sci 1981;20:726-32. 